\title{
Localization of left ventricular ischaemia in angina pectoris by cineangiography during exercise
}

\author{
B. Sharma ${ }^{1}$ and S. H. Taylor \\ From the Cardiovascular Unit, Department of Medicine, University of Leeds, Leeds General Infirmary, Leeds
}

Cineangiography of the left ventricle during exercise has been used in an attempt to define the area of ischaemic myocardium in patients suffering from angina pectoris in whom coronary artery surgery was contemplated. A correlation was established between the site of coronary artery obstruction and the area of abnormal myocardial contraction. This method of localization of regional left ventricular ischaemia may furnish useful diagnostic information when coronary reconstructive surgery is contemplated in patients with exercise-induced angina pectoris.

The surgical treatment of angina pectoris by saphenous-vein bypass graft may afford symptomatic relief in many patients in whom other treatments have failed. Surgery in this situation is dependent upon selective coronary arteriography to establish the presence and site of the obstructive lesions in the coronary arteries. However, demonstration of an obstruction in a coronary artery does not necessarily imply that the blood supply of the adjacent myocardium is diminished to such an extent that it is unquestionably producing myocardial ischaemia and pain. Furthermore, the obstructive lesions visualized by coronary arteriography are often widespread, and until now there has been no practical method of determining the importance of a particular obstruction in these patients in terms of the regional myocardial ischaemia that such a lesion may produce during exercise.

Thus the ideal approach to coronary artery bypass surgery for exercise-induced angina pectoris should include not only localization of the obstruction in the coronary arteries but also the categorical demonstration that the obstruction is associated with a definite area of myocardial ischaemia induced by exercise.

The present studies were based on the following reasoning. The myocardium is critically dependent upon adequate oxygenation, and any imbalance in blood supply and demand rapidly results in a reduction in its contractile activity. In the intact heart

Received 6 August 1974.

1 Present address: Department of Clinical Cardiology, Royal Postgraduate Medical School, Hammersmith Hospital, London WI2 OHS this is reflected in impaired contraction of the part of the wall of the ventricle to which the arterial blood supply is deficient; such areas of asynchronous contraction can be seen readily by observing the sequence of ventricular contraction after injection of radio-opaque dye into the ventricle. In patients with angina precipitated by exercise, such dyskinetic areas may be absent at rest when patients are free from pain and devoid of electrocardiographic or haemodynamic evidence of myocardial ischaemia. However, during exercise when anginal pain is present and accompanied by electrocardiographic and haemodynamic evidence of left ventricular ischaemia, the myocardium involved may be expected to develop angiographically detectable areas of altered contractile activity. This study was undertaken to investigate whether left ventricular cineangiography in such conditions is diagnostically helpful.

\section{Patients and methods}

Eleven men, average age 49 years (range 33-60), with exercise-induced angina pectoris were studied during diagnostic assessment for coronary arterial bypass surgery. The history of angina extended from $I$ to ro years and in all the patients was induced solely and repeatedly by walking. The angina was stable in that the frequency of attacks was relatively constant in each patient (6 to I8 attacks per day) and rapid relief of pain was always afforded by rest. None suffered from nocturnal or emotionally-induced pain. None was receiving drugs other than glyceryl trinitrate at the time of these studies; all had failed to respond to beta-adrenoceptor antagonists.

All were in sinus rhythm, and none was hypertensive or diabetic or had a history or electrocardiographic evi- 
dence of a previous myocardial infarction. The resting electrocardiogram was normal in all patients but during treadmill walking at I to $2 \mathrm{mph}$ on a $\mathrm{I}$ to $10^{\circ}$ incline the onset of pain was accompanied by depression of the $\mathrm{J}$ point of the ST segment in chest lead V5 more than o.I $\mathrm{mV}$ from the isoelectric line with the pattern of ischaemic configuration previously described (Thadani et al., 1973). A $2 \mathrm{~m}$ standing posteroanterior chest radiograph taken in full inspiration showed no cardiac enlargement in any patient.

The observations of the effect of exercise on the ventriculographic appearances were made during the routine diagnostic investigation of each patient before coronary surgery; no additional intravascular cannulation was involved. The technical procedures and their potential diagnostic usefulness were explained to each patient and their relatives beforehand. In all, written consent for the investigation was obtained (Medical Research Council Annual Report, 1964).

\section{Design of investigation}

Patients were familiarized with the laboratory and staff, and trained to exercise on a bicycle ergometer in the supine position at constant speed and load. A level of exercise was selected in each patient which would induce anginal pain between the second and third minutes of exercise. In all, the pain induced by this form of exercise was similar in character, intensity, and duration to that for which they sought treatment.

With the patient in the supine position the diagnostic procedure started with left ventricular cineangiography at rest. With the angiographic catheter in the left ventricle and the patient in stable sinus rhythm, left ventricular pressure and electrocardiogram were recorded over a period of 4 minutes. Pressure recording was then discontinued and $40 \mathrm{ml}$ radio-opaque dye was then injected through the same catheter into the left ventricle over a period of 5 seconds using an electromechanical pump. Simultaneous anteroposterior and lateral biplane cineangiograms were taken at a speed of 75 frames/s for 5 seconds while the patient held his breath in inspiration. Immediately after the injection left ventricular pressures were again recorded.

After these studies at rest, each patient was then exercised on the bicycle in the supine position at the speed and load that had consistently induced angina pain after 2 to 3 minutes in the preliminary training studies. Electrocardiogram and left ventricular pressure were recorded up to the onset of angina. Left ventricular pressure measurement was then discontinued and a biplane left ventricular cineangiogram was obtained in a similar way to that during the rest period, except that during exercise the pump was adjusted to deliver $60 \mathrm{ml}$ radio-opaque dye over 3 seconds, covering approximately 5 to 6 heart beats. After recovery from the exercise, selective coronary arteriography was performed.

\section{Laboratory methods}

Left ventricular cineangiography was performed by retrograde catheterization using a Judkins catheter inserted percutaneously into a femoral artery. The radioopaque dye used was Cardio Conray (May and Baker Ltd.) injected by a Gidlund pump. Selective coronary angiography was performed using Judkins catheters inserted over the guide into the femoral artery after withdrawal of the left ventricular catheter. Left ventricular and coronary arterial cineangiograms were taken with an Arriflex $35 \mathrm{~mm}$ camera at 75 frames/s.

The electrocardiogram was recorded from chest lead $V_{5}$ and calibrated externally. Records were taken up to the start of the injection of radio-opaque dye; so as not to interfere with the clarity of the cineangiogram, the chest lead was then removed and the electrocardiogram recorded from the standard limb leads. Left ventricular pressures were measured through the left ventricular multihole catheter using a strain-gauge manometer (SE Laboratories Model 234). The natural frequency of this undamped catheter-manometer system was $30 \mathrm{~Hz}$ and the damping coefficient 0.25 . The zero reference level was set $10 \mathrm{~cm}$ below the sternal angle with the patient supine.

The manometer was calibrated against an open column of saline over the range 0 to $50 \mathrm{mmHg}(0-6.7$ $\mathrm{kPa}$ ) which was arranged to span $10 \mathrm{~cm}$ recording paper; Over this range the manometer was linear to within 2 per cent. The electrocardiogram and left ventricular pressure were recorded continuously on an ultra violet light recorder (SE Laboratories Model 30r2) using only the linear arc of traverse of the galvanometers. Electrocardiographic ST segment depression was measured in chest lead $V_{5}$ from the J point to the isoelectric line joining two consecutive PR intervals as previously described (Thadani et al., 1973). Measurements were made over 5 consecutive beats with a stable isoelectric baseline. Left ventricular end-diastolic pressure was measured at the nadir of the atrial systolic pressure wave immediately before the onset of ventricular systole; pressures were averaged over two whole respiratory cycles.

\section{Results \\ Clinical observations}

At rest, the injection of dye into the left ventricle was associated with a feeling of facial warmth in all patients and transient headaches in 3; these effects subsided within 2 minutes. No patient developed anginal pain or arrhythmia during or after the injection of dye.

During exercise, the subjective effects of the radioopaque dye injection were less noticeable; the feelings of facial warmth were less obvious and none of the patients complained of headache. No patient developed arrhythmia during or after the exercise injection. The time of onset and duration of angina during the injection of dye was similar to that in the training studies in all patients.

\section{Coronary arteriography}

All patients had a distinct obstruction of 50 per cent or more of one or more of the major coronary 


\section{LEFT VENTRICULOGRAPHY}

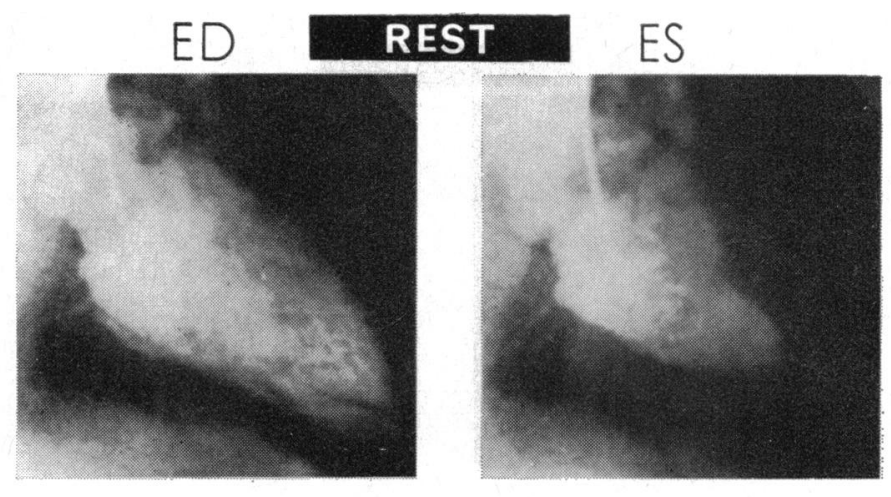

\section{EXERCISE}
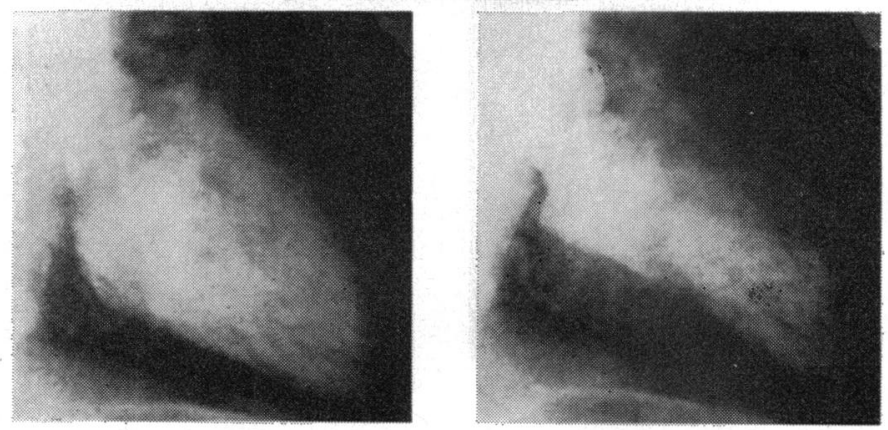

\section{CORONARY ANGIOGRAPHY}

RCA

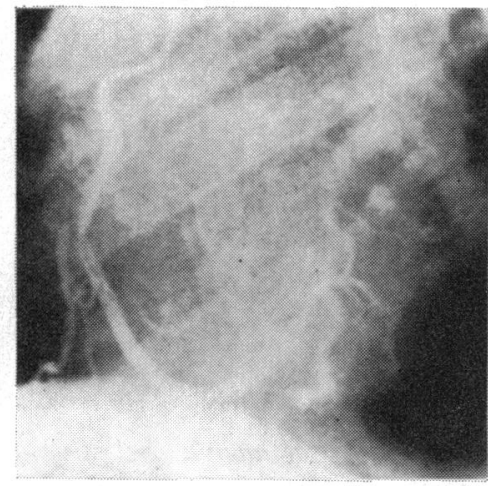

LCA

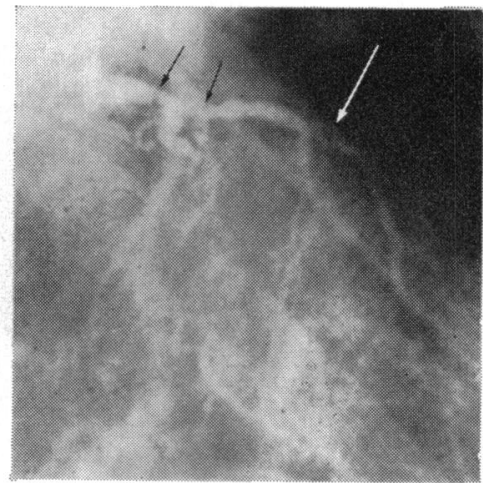

FIG. I Case No. 9, male, age 52 years; 10-year history of angina. Selective angiography of right $(R C A)$ and left $(L C A)$ coronary artery; left anterior descending artery showed significant obstructive lesions as indicated by arrows. Stills from left ventricular cineangiogram taken at end-diastole $(E D)$ and end-systole $(E S)$ at rest and during exercise. No dyskinesia at rest; area of apical dyskinesia appearing during exercise-induced angina and electrocardiographic $S T$ depression of $2.6 \mathrm{~mm}$ in chest lead $V_{5}$. 
FIG. 2 Case No. Io, male, age 36 years; one-year history of angina. Selective angiogram of right $(R C A)$ and left $(L C A)$ coronary artery; significant obstructive lesions of left anterior descending and $R C A$ as indicated by arrows. Stills from left ventricular cineangiogram taken at end-diastole $(E D)$ and end-systole $(E S)$ at rest and during exercise. No dyskinesia at rest: areas of apical and anterior wall dyskinesia appearing during exercise-induced angina and electro-cardiographic $S T$ depression of $3.0 \mathrm{~mm}$ in chest lead $V 5$. 


\section{LEFT VENTRICULOGRAPHY}

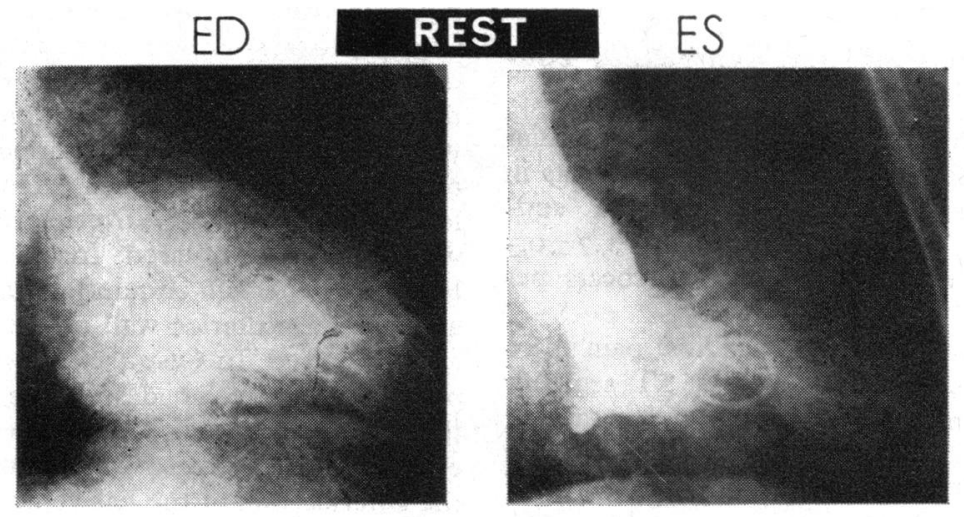

\section{EXERCISE}
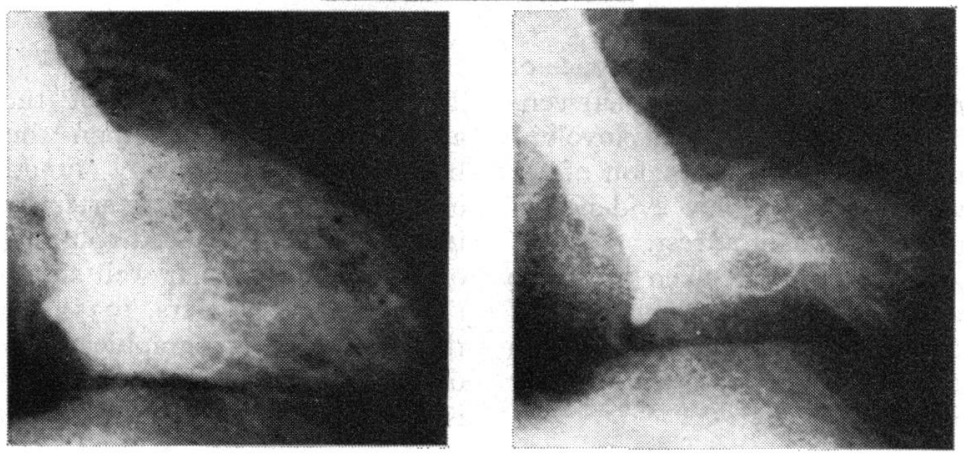

\section{CORONARY ANGIOGRAPHY}
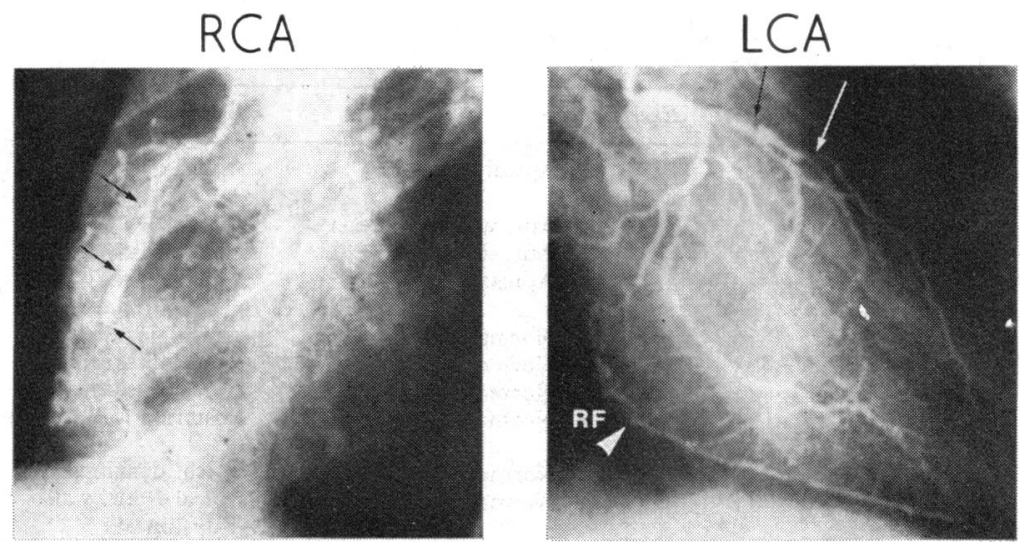

FIG. 3 Case No. II, male, age 54 years; 9-year history of angina. Selective angiogram of right $(R C A)$ and left $(L C A)$ coronary artery; significant obstructive lesions of left anterior descending and right coronary artery as indicated by arrows; also retrograde filling $(R F)$ of $R C A$ from left coronary injection. Stills from left ventricular cineangiogram taken at end-diastole $(E D)$ and end-systole $(E S)$ at rest and during exercise. No dyskinesia at rest; an area of anterior wall dyskinesia appearing during exercise-induced angina and electrocardiographic 
arteries. These changes are detailed in the Table and illustrated in 3 patients in Fig. I to 3.

Electrocardiogram and left ventricular enddiastolic pressure (Table)

At rest, the electrocardiogram and left ventricular end-diastolic pressure were within normal limits in all patients. The average left ventricular enddiastolic pressure was $12 \pm \mathrm{I} \mathrm{mmHg}$ ( $1.7 \pm 0.3$ $\mathrm{kPa}$ ), and the average heart rate $75 \pm 2$ beats per minute.

During exercise at the onset of anginal pain there was a conspicuous depression of the ST segment (average $27 \pm 0.2 \mathrm{~mm}$ ) and significant increase in left ventricular end-diastolic pressure (average $35 \pm 2 \mathrm{mmHg}(4.8 \pm 0.3 \mathrm{kPa}))$; the average heart rate was $124 \pm 4$ beats per minute.

Left ventricular cineangiography (Table, Fig. I-3)

At rest, cineangiography revealed the presence of a single discrete area of dyskinesia of the left ventricular wall in 4 of the I I patients : in 2 this involved the anterior wall and in 2 the apical region of the ventricle. There was no angiographic evidence of mitral regurgitation in any patient at rest.

During exercise cineangiograms, taken after the onset of definite anginal pain and in the presence of electrocardiographic ST depression, demonstrated a conspicuous area of dyskinesia of the left ventricular wall in all II patients.
In the 4 patients with a dyskinetic area at rest, the same area of dyskinesia became more pronounced. In the 7 patients in whom no dyskinetic area was observed at rest an unmistakable area of dyskinesia developed during exercise; in 5 in whom the left anterior descending coronary artery was involved an area of dyskinesia appeared in the apical region, and in Case 10 with extensive lesions of the left and right coronary arteries, apical and anterior wall dyskinesia appeared. In Case 8 with extensive lesions of the left circumflex and right coronary arteries the posterior wall of the left ventricle became involved. In Case 4 with complete obstruction of the left anterior descending coronary artery, there was an area of apical dyskinesia at rest; during exercise a second area of dyskinesia appeared on the anterior wall of the left ventricle which merged with the area of dyskinesia seen at rest. In none of the II patients was there any angiographic evidence of mitral regurgitation during exercise.

\section{Discussion}

The contractile activity of the myocardium is absolutely dependent upon the integrity of its blood supply, and any functionally important obstruction of a coronary artery immediately results in retarded and reduced contraction of the portion of the left ventricular wall supplied by that vessel (Tennant and Wiggers, 1935). The specific association between angiographically demonstrable areas of left ventricular dyskinesia and myocardial ischaemia has also been demonstrated in dogs

TABLE Electrocardiographic and haemodynamic correlation with coronary arteriographic and left ventricular cineangiographic findings in patients with exercise-induced angina pectoris

\begin{tabular}{|c|c|c|c|c|c|c|c|c|c|c|}
\hline \multirow[t]{2}{*}{$\begin{array}{l}\text { Case } \\
\text { No. }\end{array}$} & \multicolumn{2}{|c|}{$\begin{array}{l}\text { ST depression } \\
(\mathrm{mm})\end{array}$} & \multicolumn{2}{|c|}{ Heart rate/min } & \multicolumn{2}{|c|}{$\begin{array}{l}\text { Left ventricular } \\
\text { end-diastolic } \\
\text { pressure }(\mathrm{mmHg})\end{array}$} & \multicolumn{2}{|c|}{ Left ventricular cineangiogram } & \multicolumn{2}{|c|}{$\begin{array}{l}\text { Coronary } \\
\text { arteriography } \\
\% \text { narrowing }\end{array}$} \\
\hline & Rest & Exercise & Rest & Exercise & Rest & Exercise & Rest & Exercise & & \\
\hline $\mathbf{I}$ & 0 & 3.2 & 66 & 121 & II & 32 & Apical dyskinesia & Apical dyskinesia & $\begin{array}{l}\text { LAD } \\
\text { LCX }\end{array}$ & $\begin{array}{l}75 \% \\
50 \%\end{array}$ \\
\hline 2 & 0 & $3 \cdot 3$ & 68 & II6 & 14 & 38 & Ant. wall dyskinesia & Ant. wall dyskinesia & LCX & $75 \%$ \\
\hline 3 & 0 & 3.0 & 78 & II 8 & 12 & 36 & Ant. wall dyskinesia & Ant. wall dyskinesia & LAD & $50 \%$ \\
\hline 4 & 0 & 2.5 & 82 & 142 & I6 & 44 & Apical dyskinesia & $\begin{array}{l}\text { Apical + ant. wall } \\
\text { dyskinesia }\end{array}$ & LAD & $100 \%$ \\
\hline 5 & 0 & 2.1 & 80 & 126 & ro & 29 & Normal & Apical dyskinesia & LAD & $100 \%$ \\
\hline 6 & 0 & 3.6 & 69 & 125 & I5 & 37 & Normal & Apical dyskinesia & LAD & $75 \%$ \\
\hline 7 & 0 & 1.9 & 85 & 112 & 12 & 39 & Normal & Apical dyskinesia & LAD & $90 \%$ \\
\hline 8 & 0 & 3.0 & 78 & 128 & 13 & 35 & Normal & Posterior wall dyskinesia & $\begin{array}{l}\text { RCA } \\
\text { LCX }\end{array}$ & $\begin{array}{r}100 \% \\
50 \%\end{array}$ \\
\hline 9 & 0 & 2.6 & 80 & 126 & 8 & 24 & Normal & Apical dyskinesia & LAD & $75 \%$ \\
\hline I0 & 0 & 3.0 & 72 & 106 & I I & 34 & Normal & $\begin{array}{l}\text { Apical + ant. wall } \\
\text { dyskinesia }\end{array}$ & $\begin{array}{l}\text { LAD } \\
\text { RCA }\end{array}$ & $\begin{array}{l}75 \% \\
50 \%\end{array}$ \\
\hline II & 0 & I.8 & 63 & 125 & 12 & 38 & Normal & Ant. wall dyskinesia & $\begin{array}{l}\text { LAD } \\
\text { RCA }\end{array}$ & $\begin{array}{l}90 \% \\
50 \%\end{array}$ \\
\hline
\end{tabular}

LAD, left anterior descending coronary artery; LCX, left circumflex coronary artery; RCA, right coronary artery. 
(Pairolero, Hallermann, and Ellis, 1970). An equally specific relation appears to exist between left ventricular dyskinesia and areas of localized ischaemia in man. Detailed angiographic studies in the nonischaemic heart have demonstrated synchronous and symmetrical shortening of all myocardial segments of the left ventricle (McDonald, I970; Kong, Morris, and McIntosh, I97 I Sniderman, Marpole, and Fallen, 1973). Areas of ventricular dyskinesia are demonstrable after myocardial infarction (Herman et al., 1967; Baxley, Jones, and Dodge, 197I), and localized myocardial dysfunction is not unusual in patients with angina pectoris (Kong et al., 1971; Sniderman et al., 1973; Herman et al., 1967; Baxley et al., I97I ; Lichtlen, Baumann, and Albert, 1969). However, all previously reported angiographic studies in patients complaining of exerciseinduced angina were carried out only at rest and when the patient was without pain and had no electrocardiographic or haemodynamic evidence of left ventricular ischaemia. Hence, it is not surprising that myocardial dyskinesia could not be shown in many of these patients despite conspicuous coronary arterial lesions. In 7 of the II patients in the present study areas of left ventricular dyskinesia appeared only during exercise.

These new areas of localized left ventricular dysfunction were in the territory supplied by an obstructed coronary artery and they were apparent when the study was made during myocardial ischaemia, as evidenced by the onset of anginal pain, electrocardiographic ST depression, and a raised left ventricular end-diastolic pressure. It is reasonable to assume, therefore, that these angiographic appearances of disordered contraction of the left ventricular wall were part of this syndrome. These studies provide no evidence that anginal pain arose in the dyskinetic area. However, the association of corresponding coronary arterial obstruction, electrocardiographic evidence of left ventricular ischaemia, impairment of haemodynamic performance during exercise, and the appearance of the dyskinetic area with the onset of pain in 7 of the II patients provides reasonable circumstantial evidence for such a relation.

The pathophysiological implications of these findings are important, particularly in relation to revascularization surgery. The region of left ventricular wall showing dyskinesia only during exercise-induced stress comprises viable myocardial muscle, critically balanced at rest in terms of myocardial blood supply and demand. During exercise, the oxygen supply of this local area of muscle fails to meet demand, with resulting loss of normal contractile activity. Evidence from animal experiments suggests that areas of myocardium persis- tently dyskinetic at rest probably represent nonviable muscle (Pairolero et al., 1970). It is reasonable to assume, therefore, that revascularization surgery will have a better chance of improving an acute reversible disorder of left ventricular contraction precipitated only by the stress of exercise than of abolishing dyskinesia present at rest.

The success of the technique in demonstrating the association between the onset of anginal pain and the appearance of localized areas of dyskinesia raises a number of intriguing questions. It would also be interesting to know if the relief of pain afforded by glyceryl trinitrate, the beta-receptor antagonists, and coronary artery bypass operations are associated with changes in regional dyskinesia. Equally, it is well known that beta-receptor antagonists are not universally successful in the relief of anginal symptoms despite electrocardiographic improvement (Thadani et al., 1973; Sharma and Taylor, 1972). Similarly, saphenous vein coronary artery bypass surgery does not always result in symptomatic relief (Walker et al., I97I; Ross et al., 1972).

This radiographic technique offers a method of study that may throw light on the reasons for these therapeutic failures. In the case of bypass operations previous attention has been almost entirely directed to the demonstration of patency of such shunts. These studies suggest that left ventricular angiography may be a useful diagnostic procedure and provide relevant physiological information to supplement such morphological demonstrations.

Whatever its future usefulness in these respects the technique holds promise that it may assist in the separation of lesions of the coronary arteries unassociated with myocardial ischaemia from those resulting in regional abnormalities of ventricular contraction. Before coronary surgery is considered it is essential to ascertain that the arterial lesion it is intended to bypass is the one that is giving rise to ischaemia. Left ventricular cineangiography during exercise may allow such decisions to be made on specific functional evidence. It should, therefore, be considered as a possible addition to the diagnostic investigation of patients with exercise-induced angina pectoris in whom coronary artery surgery is contemplated.

We thank Dr. M. J. Raphael and Professor R. E. Steiner, Department of Radio Diagnosis, Hammersmith Hospital, London, for their advice with regard to interpretation of the angiographic changes.

\section{References}

Baxley, W. A., Jones, W. B., and Dodge, H. T. (I97I). Left ventricular anatomical and functional abnormalities in 
chronic post infarction heart failure. Annals of Internal Medicine, 74, 499.

Herman, M. V., Heinle, R. A., Klein, M. D., and Gorlin, R. (1967). Localized disorders in myocardial contraction: asynergy and its role in congestive heart failure. New England fournal of Medicine, 277, 222.

Kong, Y., Morris, J. J., and McIntosh, H. D. (1971). Assessment of regional myocardial performance from biplane coronary cineangiograms. American fournal of Cardiology, $27,529$.

Lichtlen, P. R., Baumann, P. C., and Albert, H. (1969). The role of left ventricular abnormalities in exerciseinduced performance in patients with severe coronary artery disease. Cardiologia, 54, 295.

McDonald, I. G. (1970). The shape and movements of the human left ventricle during systole. American fournal of Cardiology, 26, 221.

Medical Research Council Annual Report I962-63 (1964). Responsibility in investigations on human subjects. British Medical fournal, $2,178$.

Pairolero, P. C., Hallermann, F. J., and Ellis, F. H. (1970). Left ventriculogram in experimental myocardial infarction. Radiology, 95, 311.

Ross, D., Sutton, R., Dow, J., Gonzales-Lavin, L., Hendrix, G., Jefferson, K., McDonald, L., Petch, M., Smithen, C., and Sowton, E. (1972). Venous graft surgery in treat- ment of coronary heart disease. British Medical fournal, 2, 644 .

Sharma, B., and Taylor, S. H. (1972). Critical review of symptomatic, electrocardiographic and circulatory effects of adrenergic beta receptor antagonists in angina pectoris. In Proceedings of Symposium: New Perspectives in BetaBlockade. Aarhus, Denmark, May 1972.

Sniderman, A. D., Marpole, D., and Fallen, E. L. (1973). Regional contraction patterns in the normal and ischaemic left ventricle in man. American fournal of Cardiology, 31, 484 .

Tennant, R., and Wiggers, C. J. (1935). Effect of coronary occlusion on myocardial contraction. American fournal of Physiology, 112, 351.

Thadani, U., Sharma, B., Meeran, M. K., Majid, P. A., Whitaker, W., and Taylor, S. H. (1973). Comparison of adrenergic beta-receptor antagonists in angina pectoris. British Medical fournal, $\mathbf{1}, 138$.

Walker, J. A., Friedberg, H. D., Flemma, R. J., and Johnson, W. D. (1971). Determinants of angiographic patency of aortocoronary vein bypass grafts. Circulation, 44, Suppl. II, 108.

Requests for reprints to Dr. S. H. Taylor, Department of Medicine, The General Infirmary, Leeds LSI 3EX. 